\title{
News Coverage and Drug Shortages during the COVID-19 Pandemic
}

\author{
Maryaline Catillon $^{1,2}$, Maimuna S. Majumder ${ }^{1,3}$, Shannon F. Manzi ${ }^{1,3}$, Kenneth D. Mand1 ${ }^{1,3,4}$
}

${ }^{1}$ Computational Health Informatics Program, Boston Children's Hospital, Boston, Massachusetts

${ }^{2}$ Department of Economics, Harvard University, Cambridge, Massachusetts

${ }^{3}$ Department of Pediatrics, Harvard Medical School, Boston, Massachusetts

${ }^{4}$ Department of Biomedical Informatics, Harvard Medical School, Boston, Massachusetts

*Corresponding Author: Kenneth D. Mandl, Kenneth.Mandl@ childrens.harvard.edu.

Several drugs repurposed as COVID-19 treatment are in short supply. We collect data from MediaCloud and Google Health Trends about eight drugs proposed for repurposing as COVID19 treatments and reported to be in shortage by the U.S. Food and Drug Administration (FDA) from January 1, 2020 through June 30, 2020. We find that news media coverage could have contributed to shortages due to hoarding by individuals and stockpiling by institutions, and that search trends appear to accurately discriminate between individual hoarding and institutional stockpiling. 
medRxiv preprint doi: https://doi.org/10.1101/2020.10.12.20211656; this version posted October 14, 2020. The copyright holder for this preprint (which was not certified by peer review) is the author/funder, who has granted medRxiv a license to display the preprint in perpetuity.

All rights reserved. No reuse allowed without permission.

\section{News Coverage and Drug Shortages during the COVID-19 Pandemic}

\section{Background}

In recent months, multiple drugs have been proposed for repurposing as COVID-19 treatments (DPRCT), ${ }^{1,2}$ often with little evidence. Several of these drugs have come into national shortage. We assessed whether drug hoarding by individuals and drug stockpiling by institutions could be associated with media coverage.

\section{Objective}

We sought to analyze U.S. news coverage and Internet search volume for eight DPRCT reported to be in shortage by the U.S. Food and Drug Administration (FDA) from January 1, 2020 through June 30, 2020.

\section{Methods}

DPRCT were selected and categorized by SM, a pharmacist involved in federal COVID response, based on information from the American Society of Hospital Pharmacists (https://www.ashp.org/Drug-Shortages/Current-Shortages) and national and international workgroups. Because patients can directly purchase these medications, three DPRCT were characterized as able to be hoarded by individuals or stockpiled by institutions: azithromycin, famotidine and hydroxychloroquine. Five DPRCT, which are not generally purchased directly by patients, were characterized as able to be stockpiled by institutions only: cisatracurium, dexmedetomidine, continuous renal replacement therapy (CRRT), midazolam and propofol.

For each DPRCT, U.S. news volume was measured with MediaCloud's National Corpus (https://sources.mediacloud.org/\#/collections/34412234) and reported separately for (1) news about the drug excluding mention of the word "shortage" and (2) news about the drug including the word "shortage". U.S. Internet search volume was ascertained using Google Health Trends, with queries for each drug name. The shortage date announcements were based on reports in the FDA Drug Shortages Database (https://www.accessdata.fda.gov/scripts/drugshortages/default.cfm).

\section{Results}

For all DPRCT that might be stockpiled by institutions or hoarded by individuals (Figure 1), news about the drug excluding the word "shortage" and news about the drug shortage both spike before the shortage announcement. For all three drugs, Internet searches also spike before the shortage announcement.

For four of five DPRCT which might be stockpiled by institutions but are not ordinarily hoarded by individuals (Figure 2), news about the drug excluding the word "shortage" and news about the drug shortage also spike before the announcement, but for all five drugs Internet search trends are flat. 


\section{Discussion}

Though temporality does not establish causality, all but one of the DRPCT shortages were preceded by spikes in news reports, consistent with an impact of news on purchasing behaviors. ${ }^{3}$ Media coverage may trigger stockpiling by institutions and hoarding by patients. Such behaviors risk depriving patients who are dependent on those drugs for approved and widely-accepted off label uses.

Spikes in Internet searches, previously demonstrated as a potential proxy for medication purchase intent, ${ }^{5,6}$ suggest that news influenced individuals to research and acquire DPRCT that they can purchase directly. In contrast, DRPCT that could only be stockpiled by institutions did not exhibit search spikes prior to shortages. Because we don't generally expect institutions to conduct Internet searches prior to purchasing drugs, search trends appear to accurately discriminate between individual hoarding and institutional stockpiling. 
medRxiv preprint doi: https://doi.org/10.1101/2020.10.12.20211656; this version posted October 14, 2020. The copyright holder for this preprint (which was not certified by peer review) is the author/funder, who has granted medRxiv a license to display the preprint in perpetuity.

All rights reserved. No reuse allowed without permission.

\section{References}

${ }^{1}$ Jakhar D, Kaur I. Potential of chloroquine and hydroxychloroquine to treat COVID-19 causes fears of shortages among people with systemic lupus erythematosus. Nat Med. 2020;26, 632. doi:10.1038/s41591-020-0853-0

${ }^{2}$ Shuman AG, Fox E, Unguru Y. Preparing for COVID-19 Related Drug Shortages. Annals of the American Thoracic Society, (ja). 2020. doi: 10.1513/AnnalsATS.202004-362VP

${ }^{3}$ Walsh-Childers K. Mass Media and Health: Examining Media Impact on Individuals and the Health Environment. London, UK: Routledge; 2016.

${ }^{4}$ Liu M, Caputi TL, Dredze M, Kesselheim AS, Ayers JW. Internet Searches for Unproven COVID-19 Therapies in the United States. JAMA Intern Med. 2020;180(8):1116-1118. doi:10.1001/jamainternmed.2020.1764

${ }^{5}$ Rivera, Jessica and Gupta, Shagun and Ramjee, Divya and El Hayek, Ghinwa and El Amiri, Nisrine and Desai, Angel and Majumder, Maimuna S., Evaluating Interest in Off-Label Use of Disinfectants for COVID-19 with Google Trends (June 29, 2020). Available at SSRN:

https://ssrn-com.ezp-prod1.hul.harvard.edu/abstract=3638653 
medRxiv preprint doi: https://doi.org/10.1101/2020.10.12.20211656; this version posted October 14, 2020. The copyright holder for this preprint

(which was not certified by peer review) is the author/funder, who has granted medRxiv a license to display the preprint in perpetuity.

All rights reserved. No reuse allowed without permission.

\section{Figure Legends}

Figure 1. News volume, Internet search trends, and shortage date for azithromycin, famotidine and hydroxychloroquine. News volume (7-day rolling average), from

MediaCloud's U.S. National Corpus is reported separately for (1) news about the drug excluding mention of the word "shortage", labelled "News: Drug" and (2) news about the drug including the word "shortage", labelled "News: Shortage." Internet search volume was measured using Google Health Trends, with queries for each drug name. Shortage date announcements are from the Food and Drug Administration (FDA) Drug Shortages Database.

Figure 2. News volume, Internet search trends and shortage date for Cisatracurium, Continuous renal replacement therapy, dexmedetomidine, midazolam, and propofol. News volume (7-day rolling average), from MediaCloud's U.S. National Corpus, is reported separately for (1) news about the drug excluding mention of the word "shortage", labelled "News: Drug" and (2) news about the drug including the word "shortage", labelled "News: Shortage." Internet search volume was measured using Google Health Trends, with queries for each drug name. Shortage date announcements are from the Food and Drug Administration (FDA) Drug Shortages Database. 

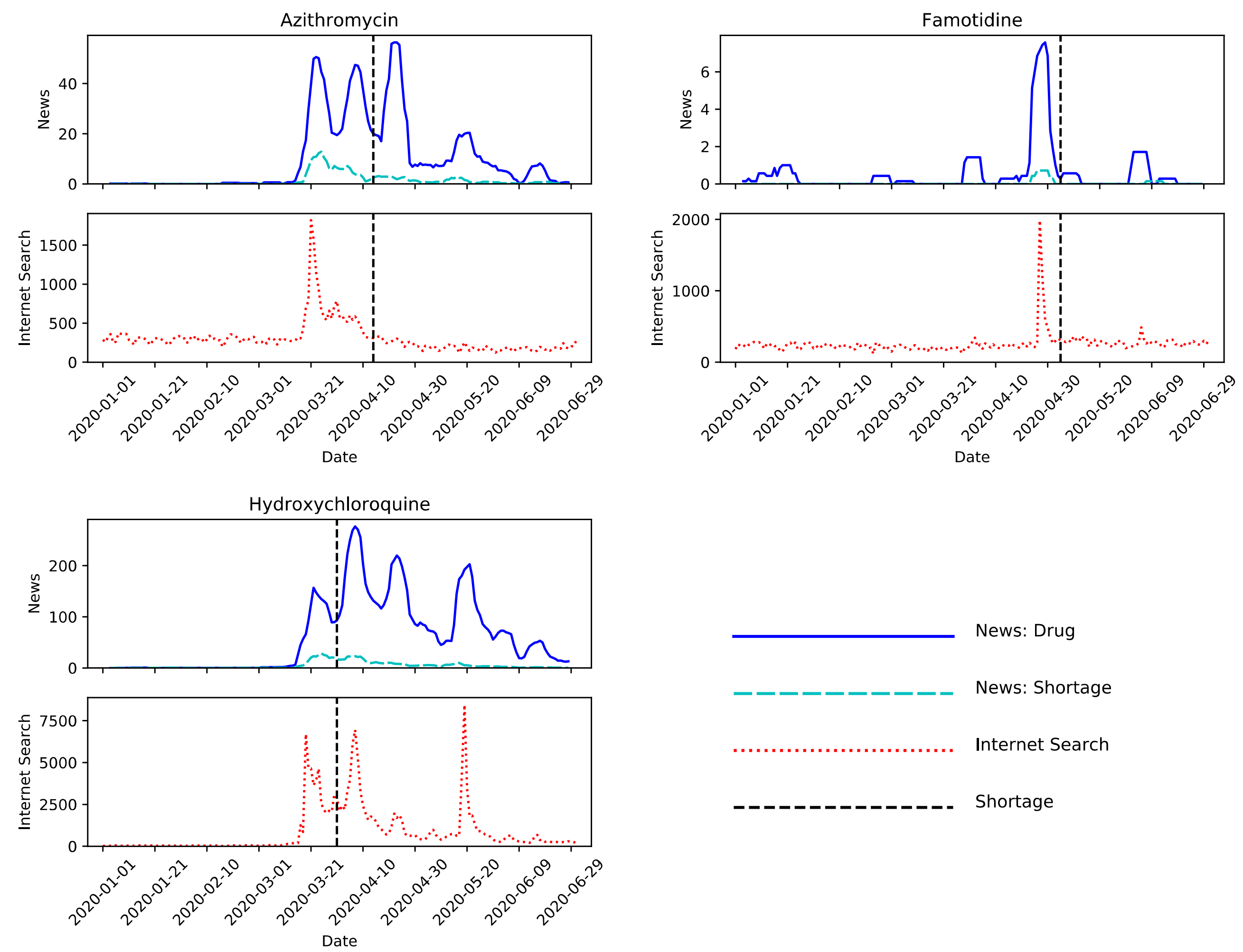

News: Drug

News: Shortage

Internet Search

Shortage 

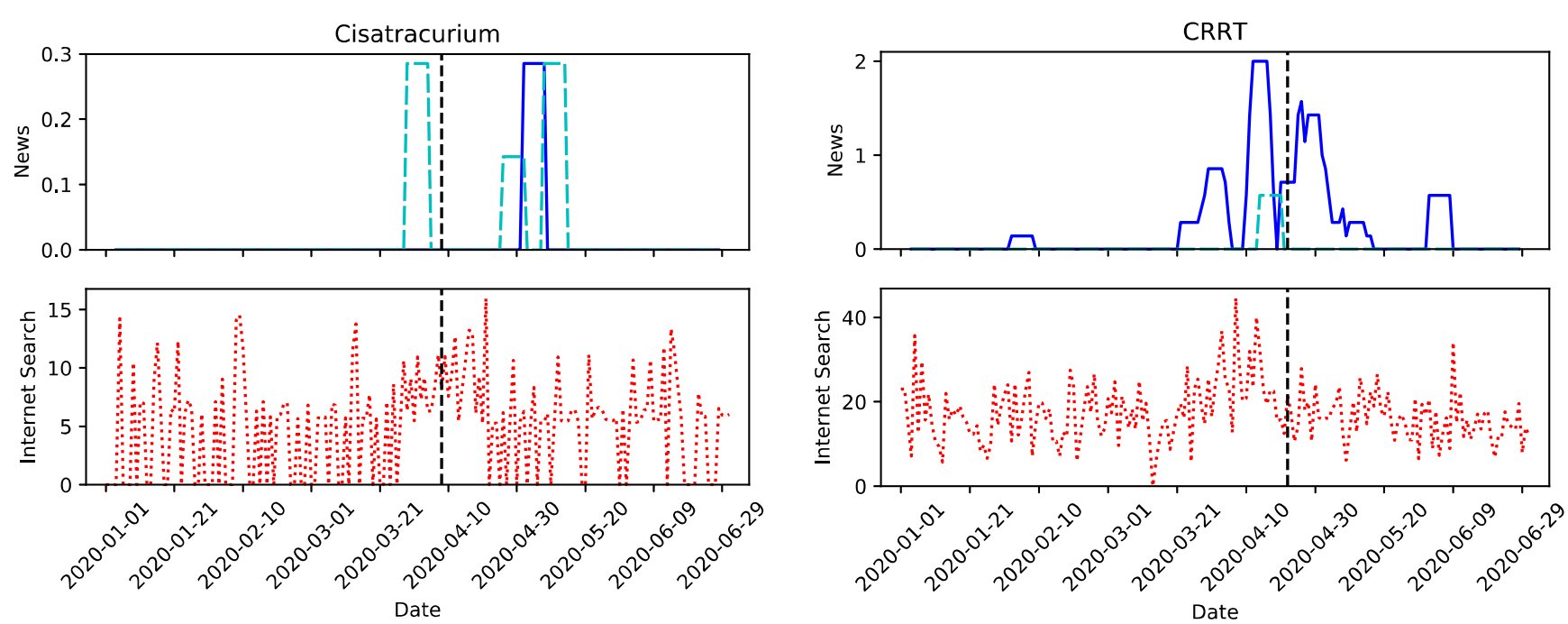

Midazolam
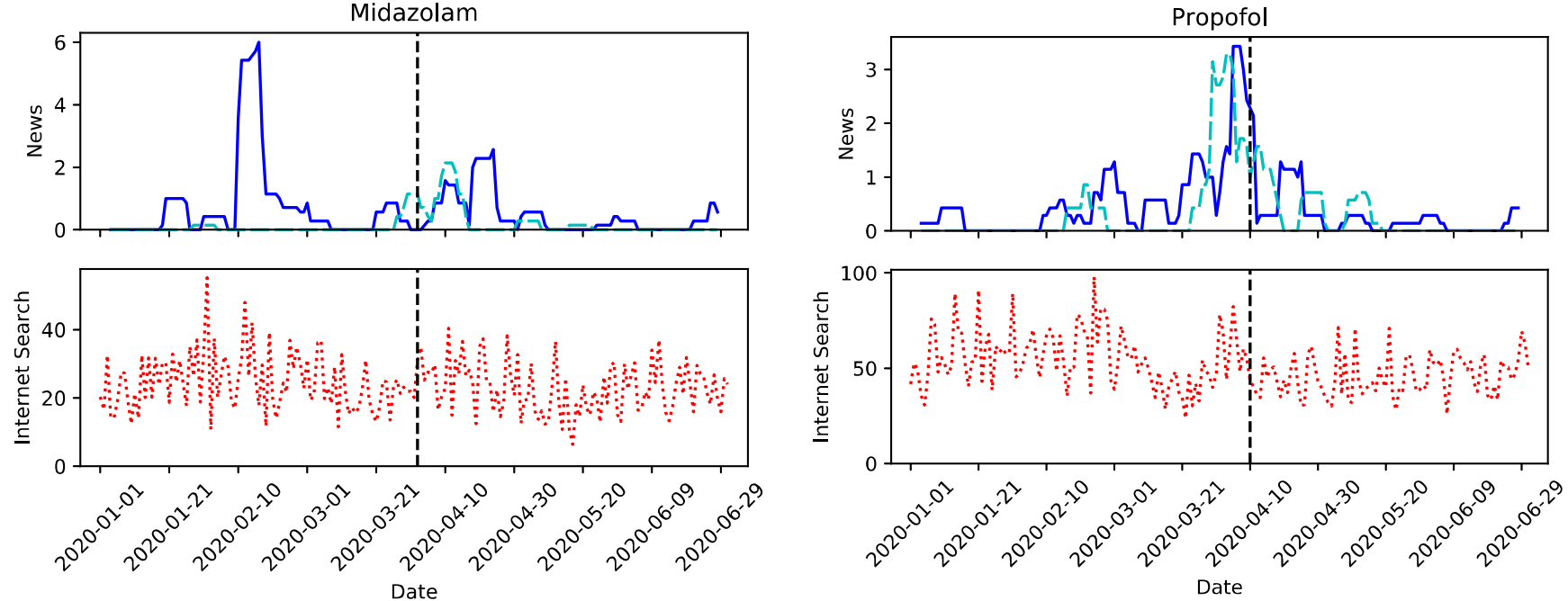

Dexmedetomidine
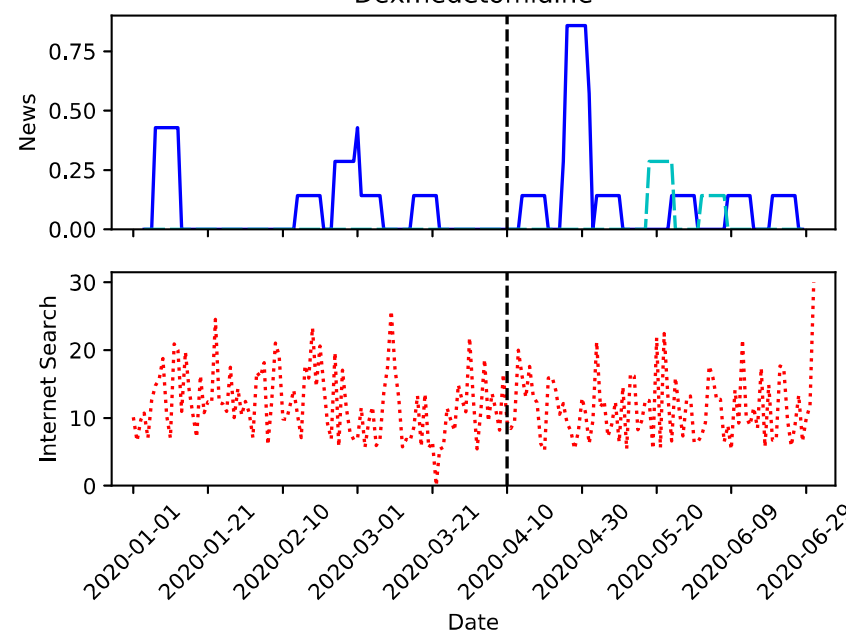

News: Drug

News: Shortage

nternet Search

Shortage 